\title{
Tips for Programming the Speech Processor
}

\author{
D. Popova; S. Varbanova; Ig. Stancheva, \\ M. Milkov*; TM. Popov; V. Marinov \\ Medical University Sofia - ENT Department; UMBAL „Tzaritza Yoanna-ISUL“, Sofia, \\ "Medical University Varna
}

$\mathrm{T}$ The goal of the device programming is to adjust the device so that it can convert acoustic input signals into a usable electric dynamic range for each stimulated electrode.

There are basic psychophysical measures, that we must obtain. The degree of difficulty depends on a number of factors:

$\checkmark$ age;

- mental status;

- length of deafness;

- number of useful intracochlear electrodes.

Cochlear implant recipients must understand soft and loud speech in quiet and noisy situations. For that it is necessary to select this range of speech intensities from the input signal and fit this range to the electrical stimulation levels of the implant recipients, while at the same time minimizing the background noise.

On normal hearing people we can detect the softest sound in a $0 \mathrm{~dB}$ in threshold levels (HTL - ANSI 1969). Sounds above $100 \mathrm{~dB}$ are uncomfortably loud. This is a usable dynamic range for normal hearing listeners. They are able also to discriminate intensity differences of $0,3 \mathrm{~dB}$ to $2 \mathrm{~dB}$ (Moore et al., 1997) and also there are 100 loudness steps available in normal dynamic range of hearing (Nealson et al., 1996; Shannon, 1993).

For cochlear implant patients this dynamic range is smaller than that of a normal hearing person. The average clinical dynamic range on a $\mathrm{dB}$ scale are about $3 \mathrm{~dB}$ to $6 \mathrm{~dB}$ (Halkins, 1998). The number of steps available in this narrow dynamic range is about 6 to 45 steps (Nelson et al., 1996).

The speech coding strategies are not able to code all sound information in the redundant speech signal and they present the reduced amount of speech information. The different reason of pathology of deafness may limit the amount of speech information, that can be transmitted by the auditory pathway.

In the real world very few speech and helpful sounds have intensities below $30 \mathrm{~dB}$ SPL (soft speech is about $50 \mathrm{~dB}$ SPL and loud speech is 90 dB SPL - Byrne et al. 1994). The short term intensity range of speech between the most intense vowel and the least intense consonant is about 30 dB (Byrne et al. 1994).

To maximize the coding of input signal intensity for speech the input of the speech processor needs to be adjusted to different signal intensities and then code input dynamic range of the output dynamic range of the recipient, which is 7 to 10 dB average.

The cochlear implant patients have access to the short intensity range of speech and the best opportunity to use loudness cues in speech perception. In the presence of noise the level of speech intensity change with the level of background noise. Pearsons et al., 1997 states that the overall speech 
level increases at about $0,6 \mathrm{~dB}$ for every $1 \mathrm{~dB}$ increase in noise level, thus the difference between the signal and noise levels decreases while the level of noise increases.

When we speak about input dynamic range, coding is compressing a large input range of about $60 \mathrm{~dB}$, which will cover the wide range of speech levels of implant recipient's output dynamic range. In this case, when we use a wide input dynamic range, we compress both the signal and noise at the same time. With a smaller input dynamic range we minimize the audibility of the background noise.

Another important factor is the number of loudness steps that the implant recipients receive within the dynamic range.

If the patient has one large input dynamic range he would be able to perceive speech information with amplitude variations, in comparison to the smaller input dynamic range which can't code the amplitude information. These methods are:

- electrically evoked auditory brainstem response (EABR);

- electrically evoked acoustic reflex thresholds (EART);

- also pre - and intraoperative investigations.

In the problematic patients we incorporate these methods into the fitting process. Device programming involves selecting and individually fitting the speech processing strategy. Processing strategies are used to translate incoming acoustic stimuli into electrical pulses that stimulate auditory nerve fiber.

The stimulation of the auditory nerve with trains of trains of repetitive electrical pulses underlies the treatment of profound deafness. Normally acoustic signal results in relatively stereotyped activity of auditory nerve fibers, which is transformed and encoded in various discharge patterns by different cell types in the cochlear nucleus.

The interaction between auditory nerve fibers and cochlear nucleus nevrons in conditions of electrical stimulation can be a crucial steps for improving the strategy of coding sounds (Wison et al., 1991; Rubinstain et al., 1999).

Litvak (2001) has been demonstrated that significant improvement in speech recognition and a more natural pattern of activity in auditory nerve fibers can be achieved using high rate pulsative stimulation. The strategies of coding acoustic signals by electrical pulses applied to the auditory nerve in modern cochlea implants control the neuronal activity along the auditory pathways produced by electrical stimulation.

More neural sounds may be obtained in cochlear implant patients if the parameters of electrical stimuli are adjusted to match the type of activity normally produced by acoustic stimulation.

The electrical stimulation at high rates produce neural activity closer to the natural patterns of neuronal activity than electrical stimulation delivered at low rates. One of the advantages of high rate stimulation is attributed to the possibility of coding with fine temporal resolution.

The strategies of coding acoustic signals by electrical pulses applied to the auditory nerve in modern cochlea implants control the neuronal activity along the auditory pathways produced by electrical stimulation. More neural sounds may be obtained in cochlear implant patients if the parameters of electrical stimuli are adjusted to match the type of activity normally produced by acoustic stimulation. The electrical stimulation at high rates produce neural activity closer to the natural patterns of neuronal activity than electrical stimulation delivered at low rates. One of the advantages of high rate stimulation is attributed to the possibility of coding with fine temporal resolution.

The clinical development of the patient correlates to the deprivation and the plasticity of the neural system and is related to; the length of deafness, age of implantation and their effect on the performance with a cochlear implant.

Step by step we increase thresholds, MCL and UCL of el. stimulation. We use simple loudness scaling-little, good, strong. Before every fitting we make pure tone play- audiometry in free field and after discussion change the programs of the SP. Then we observe their reactions of discomfort and auropalpebral reflexes. 
ДЯСНО Ухо

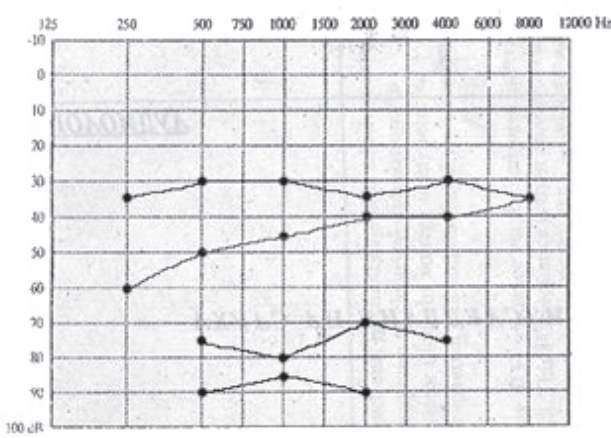

ТОНААНА АУДИОМЕТРИЯ

МSBO УХO

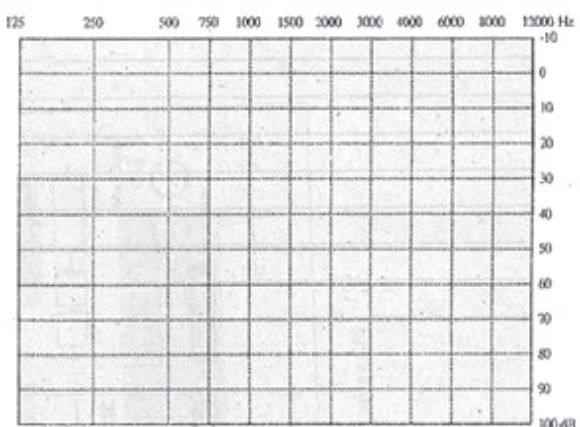

The audiograms of the children in free field show every time how the thresholds of hearing change after every new fitting.

We observe a good tendency of decreasing from $80-90 \mathrm{~dB}$ to $30-35 \mathrm{~dB}$. As a result from hard rehabilitation and programming our patients receive adequate hearing changes and develop speech and language abilities.

Our experience with cochlear implantation showed improvement in the following areas:
- speech understanding,

understanding speech in noise,

- telecommunications,

- language development,

- learning in mainstream school,

- possibility for learning a foreign language,

- social communication.

\section{References:}

1. Попова Д., С. Върбанова, Сп. Тодоров, Ор. Стоянов, Т. Попов. Кохлеарна имплантация - лечение на глухотата. Medical Magazine 2015 21: $38-40$.

2. Върбанова С., Д. Попова, Т. Попов, С. Тодоров, О. Стоянов, И. Станчева. Промени в подбора на пациенти за кохлеарна имплантация. Международен бюлетин по оториноларингология, IX, 2013, N 3, 7-12.

3. Varbanova S., D. Konov, Sp. Todorov, O. Stoyanov, V. Marinov. Clinical application of tympanometry in the topic diagnosis of hearing loss - A study from Bulgaria. International Journal of Current Research and Academic Review, vol. 3(5), 2015, May, (ISSN 2347-3215) (IF 1.215).

4. Busby PA, Roberts SA, Tong YC, Clark GM. Results of speech perception and speech production training for three prelingually deaf patients using a multiple-electrode cochlear implant. Br. J. Audiol. 1991; 25(5): 291-302.

5. Busby PA, Clark GM. Gap detection by early-deafened cochlear-implant subjects. J. Acoust. Soc. Am. 1999; 105(3): $1841-1852$.

6. Cazals Y, Pelizzone M, Kasper A, Montandon P. Indication of a relation between speech perception and temporal resolution for cochlear implantees. Ann. Otol. Rhinol. Laryngol. 1991;100(11):893-895.[

7. Cazals Y, Pelizzone M, Saudan O, Boex C. Low-pass filtering in amplitude modulation detection associated with vowel and consonant identification in subjects with cochlear implants. J. Acoust. Soc. Am. 1994; 96(4): 2048-2054.

8. Dawson PW, Clark GM. Changes in synthetic and natural vowel perception after specific training for congenitally deafened patients using a multichannel cochlear implant. Ear. Hear. 1997; 18(7): 488-501.

9. Eggermont JJ, Ponton CW. Auditory-evoked potential studies of cortical maturation in normal hearing and implanted children: correlations with changes in structure and speech perception. Acta Otolaryngol. 2003; 123(2): 249-252.

10. Faulkner A. Adaptation to distorted frequency-to-place maps: implications for cochlear implants and electro-acoustic stimulation. Audiol. Neurootol. Suppl. 2006; (1): 21-26.

11. Fu Q-J, Shannon RV, Wang X. Effects of noise and number of channels on vowel and consonant recognition: Acoustic and electric hearing. J. Acoust. Soc. Am. 1998b; 104(6): 3586-3596. 